\title{
A BIOGRAFIA ESCRITA POR REILA GRACIE E AS FONTES JORNALÍSTICAS: REVISANDO A HISTÓRIA HEGEMÔNICA
}

\author{
A BIOGRAPHY WRITTEN BY REILA GRACIE AND JOURNALISTIC SOURCES: \\ REVIEWING A HEGEMONIC HISTORY
}

\author{
LA BIOGRAFÍA ESCRITA POR REILA GRACIE Y LAS FUENTES \\ PERIODÍSTICAS: REVISIÓN DE LA HISTORIA HEGEMÓNICA
}

\author{
Riqueldi Straub Lise*, Natasha Santos*, Fernando Renato Cavichiolli*, \\ André Mendes Capraro*
}

Palavras chave:

Jiu-jítsu.

Artes marciais.

Fontes de dados.

História.

\begin{abstract}
Resumo: 0 objetivo da presente pesquisa consiste em relacionar a narrativa desenvolvida na biografia Carlos Gracie: o criador de uma dinastia, de 2008, e a perspectiva veiculada por alguns periódicos cariocas do início do século XX, no que se refere ao estabelecimento e disseminação do jiu-jítsu e dos combates intermodalidades no Brasil, em especial na cidade do Rio de Janeiro. Para tanto, utilizaram-se os preceitos metodológicos acerca das particularidades das fontes biográficas e jornalísticas. A partir da análise das referidas fontes, pode-se pensar a hipótese de que Reila Gracie tenha lançado mão de uma tradição inventada, por meio da biografia e aproveitando-se da dimensão ficcional peculiar a tal gênero, com sentido de atribuir aos integrantes da família Gracie o pioneirismo do jiu-jítsu e dos combates intermodalidades no Brasil.
\end{abstract}

Keywords:

Jiu Jitsu.

Martial arts.

Data sources.

History.
Abstract: This research discusses the narratives developed in the 2008 biography Carlos Gracie: o criador de uma dinastia and the perspective spread by some Rio de Janeirobased newspapers during the early $20^{\text {th }}$ century on the establishment of jiu jitsu and interfight competitions in Brazil. Therefore, we used methodological frameworks about the particularities of biographical and journalistic sources. From the analysis of those sources, it is possible to think about the hypothesis that Reila Gracie used an invented tradition, through biography and its peculiar fictional dimension, thus establishing the Gracie family as a pioneer in jiu-jitsu and inter-fight competitions in Brazil.

Palabras clave: Jiu Jitsu. Artes marciales. Fuentes de datos. Historia.
Resumen: El objetivo de esta investigación es relacionar la narrativa desarrollada en la biografía Carlos Gracie: o criador de uma dinastia, de 2008, con la perspectiva transmitida por algunos periódicos de Rio de Janeiro a inicios del siglo XX, en lo que se refiere al establecimiento y diseminación del jiu-jitsu y de los combates entre modalidades en Brasil, especialmente en la ciudad de Río de Janeiro. Para ello, hemos utilizado los preceptos metodológicos sobre las particularidades de las fuentes biográficas y periodísticas. A partir del análisis de estas fuentes, es posible pensar la hipótesis de que Reila Gracie haya hecho uso de una tradición inventada, a través de la biografía, aprovechándose de la dimensión ficcional propia de este género, en el sentido de atribuir a los integrantes de la familia Gracie el pionerismo en el jiu-jitsu y los combates entre modalidades en Brasil.
*Universidade Federal do Paraná (UFPR). Curitiba, PR, Brasil. E-mail: liseriqueldi@gmail.com

Recebido em: 31-05-2016 Aprovado em: 31-03-2017

DOI: http://dx.doi.org/10.22456/1982-8918.65100

\section{(c) (1) () Licence}




\section{INTRODUÇÃO}

Ao tratar a respeito do início da prática de jiu-jítsu e do surgimento dos chamados combates intermodalidades ${ }^{1}$ no Brasil, ou, sob um viés da tradicional Escola Metódica (SILVA; SILVA, 2005), ao abordar sobre quem teria originado tais práticas, verifica-se, segundo Lise (2014), o uso recorrente da biografia de Carlos Gracie, escrita por sua filha Reila Gracie, para embasar tal discussão. Essa recorrência reforça uma narrativa amplamente difundida, já que 0 uso da referida obra se estabelece como meio de provar determinadas interpretações, sem que haja o devido questionamento, seguido por uma investigação pautada em fontes históricas.

Em se tratando do gênero biográfico, pode-se situá-lo naquilo que Ginzburg (2004) aborda como literatura de fronteira, a qual corresponde às narrativas com determinado nível de pretensão à verdade, muito embora tragam, também, um viés fictício - daí a colocação desse tipo de obra entre aquilo que é contextual e aquilo que é criação. É nesse entremeio que se pode localizar Carlos Gracie: o criador de uma dinastia (2008), biografia em que a autora, Reila Gracie, se propõe a discorrer acerca da participação de integrantes da família Gracie, em especial Carlos, no desenvolvimento e disseminação dos combates intermodalidades, denominados por Reila de "vale-tudo", e do jiu-jítsu - arte marcial de origem japonesa, que ao longo das primeiras décadas do século XX é introduzida no Brasil como uma possibilidade de defesa pessoal e que, mais tarde, passou por um processo de esportivização, tornando-se uma modalidade esportiva reconhecida e regulamentada uniformemente.

Havendo, portanto, a predominância de uma história memorialista, que atribui, exclusivamente, aos membros da família Gracie a disseminação do jiu-jítsu e a introdução dos desafios intermodalidades no Brasil, é possível observar alguns exemplos de textos que reforçam a possibilidade da existência de uma "tradição inventada"2, vinculando, por exemplo, a gênese dos confrontos intermodalidades à ação dos integrantes da referida família. Vale ressaltar que o discurso de Reila Gracie acerca da suposta introdução do vale-tudo ${ }^{3}$ no país é reproduzido por dezenas de matérias em revistas, jornais, sites da internet e até nos próprios textos acadêmicos; ou seja, ele reverbera com intensidade, provavelmente devido ao capital simbólico (BOURDIEU, 2003) de que a narradora é detentora.

Seguem, então, alguns exemplos. Em extensa matéria publicada no portal de lutas do site IG Eduardo Oliveira afirma que: "A primeira luta do então 'vale-tudo' que se tem registro no mundo aconteceu em 1924, no Rio de Janeiro, quando Carlos Gracie enfrentou o estivador Samuel, conhecido atleta da capoeira" (OLIVEIRA, 2011). Em junho de 2014 a revista Tatame Online publica um artigo sobre a história do MMA no qual discorre:

Os primeiros registros datam do século VII a.C., quando os gregos criaram 0 pankration, uma mistura de boxe com luta livre e que chegou a ser o esporte mais popular dos jogos Olímpicos da Antiguidade. 0 nascimento daquilo que se tornaria o embrião do MMA ocorreu somente no século passado, graças ao

\footnotetext{
1 Por combates intermodalidades entendem-se aquelas disputas de lutas nas quais são permitidas o uso de técnicas de modalidades distintas. 2 Hobsbawm e Ranger, na obra A invenção das tradições, consideram tradição inventada "Um conjunto de práticas, normalmente reguladas por regras tácitas ou abertamente aceitas. Tais práticas de natureza ritual ou simbólica visam inculcar certos valores e normas de comportamento através da repetição, o que implica, automaticamente, uma continuidade em relação ao passado, aliás, sempre que possível, tenta-se estabelecer uma continuidade com um passado histórico apropriado" (HOBSBAWM; RANGER, 2012, p. 12).

3 Possivelmente, o termo "vale-tudo" tenha se originado a partir da dificuldade em estabelecer regras para os confrontos entre diferentes modalidades. Dessa maneira, o vocábulo parece designar aqueles confrontos nos quais seriam admitidas técnicas próprias de cada modalidade de esportes de combates e artes marciais. Para esta pesquisa tais confrontos serão denominados intermodalidades.
} 
brasileiro Carlos Gracie, que aprendeu judô e o transformou de tal forma que criou uma nova modalidade chamada de jiu-jítsu (TATAME ONLINE ${ }^{4}$, 2014).

O portal de lutas News MMA reitera que: "Antigamente chamado de Vale Tudo, o esporte foi criado no Brasil na década de 30 pela família Gracie, com o objetivo de mostrar a superioridade técnica da arte marcial difundida entre o clã: o Jiu-jjtsu Gracie" (NEWS MMA, 2012). Rudnick (2012) - em matéria no site da Gazeta do Povo, jornal de maior circulação no estado do Paraná - estabelece uma cronologia do desenvolvimento dos confrontos intermodalidades e do jiu-jítsu no Brasil da seguinte maneira:

1915 - O jiu-jítsu chega ao Brasil com o japonês Mitsuyo Maeda. Em Belém-PA, ele conhece Gastão Gracie, fato crucial para o nascimento das artes marciais mistas (MMA) quase nove décadas depois. Carlos Gracie, um dos oito filhos de Gastão, começa a treinar jiu-jítsu. Ele ensina a 'arte suave' aos irmãos, mas é Helio, o mais franzino, quem mais se destaca. Eles aperfeiçoam as técnicas de chão e criam o jiu-jítsu brasileiro (BJJ).

Década de 30 - Para provar que o BJJ é mais eficiente do que qualquer outro tipo de luta, nasce o vale-tudo. Os duelos agitam o Rio de Janeiro - quase sempre com Carlos ou Helio finalizando os adversários (RUDNICK, 2012 - Grifos do autor) ${ }^{5}$.

Nunes e Rubio (2012), em um artigo cujo objetivo está centrado em uma genealogia dos medalhistas olímpicos de judô, discorrem: "O enfoque principal do jiu-jítsu brasileiro sempre foi o combate real com ênfase na luta no solo. Os Gracie ainda modificaram os nomes das técnicas, "abrasileirando" algumas e criando outros termos para identificar as mesmas ações técnicas, ensinadas nas escolas de judô Kodokan" (NUNES, RUBIO, 2012). Ao analisar os critérios de noticiabilidade da revista Tatame, Marques, Gonçalves e Kroth (2013) afirmam que: "O antecessor das Artes Marciais Mistas (MMA) foi o Vale-Tudo que surgiu do interesse da família Gracie mostrar a superioridade do Jiu-Jitsu Brasileiro sobre as demais lutas" (MARQUES; GONÇALVES; KROTH, 2013, p. 3).

A partir das referências acima citadas, é possível perceber o consenso de que tanto o jiu-jítsu quanto o vale-tudo (e também o MMA futuramente) têm suas origens atribuídas à família Gracie.

Dessa forma, o objetivo da presente pesquisa consiste em relacionar a narrativa apresentada na biografia de Carlos Gracie, de 2008, e a perspectiva veiculada por alguns periódicos cariocas do início do século XX, no que se refere ao estabelecimento e disseminação do jiu-jítsu e dos combates intermodalidades no Brasil. A partir desse contraponto, questionase: quais as relações entre os jornais e a referida biografia, quanto à abordagem do papel dos Gracie no processo de disseminação e estabelecimento do jiu-jítsu e dos combates intermodalidades?

A escolha pelo uso de fontes jornalísticas ${ }^{6}$ se deu pelo fato não existirem, no Brasil, naquele período, instituições formais que regulamentassem os confrontos intermodalidades. O que se percebeu ao longo da pesquisa é que cabia aos jornais, de certa forma, organizar e promover tais embates, além de, algumas vezes, regulamentar essas práticas. Daí a escolha por tal tipo de fonte, tendo em vista a ausência de outra documentação, inclusive a de cunho

4 Disponível em: <http://tatameonline.com/a-historia-do-mma-vale-tudo-saiba-tudo-sobre-o-ufc-e-o-pride/>. Acesso em: 12 maio 2016.

5Disponível em: http://www.gazetadopovo.com.br/esportes/berco-do-vale-tudo-brasil-vira-o-mercado-mais-cobicado-do-ufc-7rmjwi7wir9j9h 5h3x3gyi3bi. Acesso em: 12 maio 2016.

60 amplo levantamento de fontes, realizado neste estudo, foi possibilitado pelo site da Hemeroteca Digital, disponível em: <http://bndigital. bn.br/hemeroteca-digital/>. 
oficial. No decorrer deste estudo foi possível constatar que a função do jornal - no caso específico do estabelecimento e popularização dos confrontos intermodalidades -, para além de servir de divulgador, era também de agente ativo nessa dinâmica.

Pensando no jornal enquanto fonte, cabe destacar - tal como Tania Regina de Luca (2008) aponta - que a escrita historiográfica por meio da imprensa é relativamente recente e bastante próxima das transformações sofridas pela disciplina da História. Estas modificações se vinculam aos entrelaçamentos entre a escrita científica e a busca pela verdade. A busca de uma verdade preconizada pelas escolas ${ }^{7}$ vigentes nesse período (século XIX e início do $X X)$, bem como apoiada na vertente positivista, apontava para o uso de fontes marcadas pela objetividade, fidedignidade, neutralidade e credibilidade. Desse modo, estabelecia-se uma hierarquia qualitativa dos tipos de fontes a serem utilizadas, que deveriam prezar pela neutralidade até então compatível aos documentos oficiais. Fontes como jornais, literatura, cartas ou diários, que em comum trazem a característica de estarem cercados pelo interesse (políticos, culturais, de classe, etc.), compromisso (seja com a estética, seja com o editorial) e subjetividade, eram compreendidas como inadequadas para recuperação do passado - tendo em vista esse afastamento da fidedignidade (VIEIRA et al. 1984). Ao jornal caberia, portanto, a função de registrar fragmentos do presente, documentado sob a égide de compromissos, paixões e impulsos, os quais ainda estavam sujeitos a distorções, subjetividades e mais fragmentação.

\section{HISTORICIZANDO A BIOGRAFIA DE CARLOS GRACIE}

No ano de 2008 foi lançada no Brasil, pela editora Record, a biografia Carlos Gracie: 0 criador de uma dinastia. A obra idealizada e escrita por Reila Gracie, filha de Carlos, descreve a história da referida família desde a chegada dos primeiros imigrantes escoceses desta linhagem ao Brasil, no ano de 1826, até o início dos anos 2000. O livro, considerado pela autora como uma "arqueologia familiar", pretende "contar como tudo realmente aconteceu" 8.

Ao longo das 570 páginas que compõem essa biografia, Reila destaca uma série de aspectos que são tangenciados pela trajetória de vida de Carlos Gracie. A obra começa com a narrativa da morte de Carlos, a partir daí o livro se divide em duas partes - as quais somam 42 capítulos - mais um epílogo. A partir de uma série de relatos, Reila descreve o aprendizado das técnicas de jiu-jítsu, ensinadas por Mitsuyo Maeda; a importância dos confrontos intermodalidades para o reconhecimento do jiu-jítsu como arte marcial eficiente em combates reais; os conflitos internos ocasionados pelas relações de poder dentro da própria família; a dieta Gracie, elaborada por Carlos; entre outros capítulos não menos importantes.

Para a elaboração desta biografia, Reila Gracie, em um período de nove anos, entrevistou cerca de 140 agentes que participaram direta ou indiretamente dos eventos relatados no livro. Além das entrevistas, a autora se utilizou, embora em menor quantidade, de algumas fontes jornalísticas ou crônicas nas quais os integrantes da família eram citados (GRACIE, 2008). Portanto, pode-se aqui afirmar que o livro possui um caráter majoritariamente memorialista, cuja seleção dos agentes participantes fazem parte da autonomia da autora em relação a sua obra (CANDIDO, 2000).

7 Para uma discussão mais profunda sobre a concepção de História, sua relação com a verdade e suas escolas, ler: Keith Jenkins em $\mathbf{A}$ História Repensada (2011) e Peter Burke em A Escola dos Annales (1997).

8 Tais informações estão disponíveis no epílogo da própria obra. 
Ora, quanto ao gênero biográfico, destaca-se que:

A narrativa biográfica supõe uma modalidade de escrita da História profundamente imbricada nas subjetividades, nos afetos, nos modos de ver, perceber e sentir o outro. Talvez este seja o grande desafio do trabalho biográfico: ao falar do seu personagem, o biógrafo, de certa forma, fala de si mesmo, projeta algo de suas emoções, de seus próprios valores e necessidades (AVELAR, 2012, p. 168).

Esse "mergulho na alma" do biografado (BORGES, 2012, p.213) torna propício o tratamento da biografia enquanto um gênero de fronteira (GINZBURG, 2004), isto é, como uma narrativa localizada na linha tênue entre ficção e contexto, já que nenhuma ilha é apenas uma ilha, mas dialogam entre si. Contempla, portanto, aspectos textuais e contextuais. Sobre a literatura - 0 que se estende ao gênero de fronteira -, Candido (2000) aponta para a fusão entre texto (estética literária e a autonomia do autor) e contexto (elementos históricos e sociais) como a constituinte da obra, que deve ser considerada pelo pesquisador, o qual necessita compreender como o contexto social, junto a elementos biográficos do próprio escritor, se manifesta na produção. Com sentido de ampliar a reflexão acerca dessa obra, torna-se aqui, portanto, necessário discorrer acerca do contexto no qual o livro foi lançado.

Reila, filha de Carlos Gracie, é uma editora de artes plásticas, mãe de duas filhas e um filho, Roger Gracie, que figura como um dos grandes lutadores de jiu-jítsu de todos os tempos. A autora revela no epílogo da obra a principal motivação que a levou a escrever esse polêmico livro: o suposto esmaecimento da figura de Carlos Gracie na construção da história do jiu-jítsu no Brasil e na constituição de uma dinastia familiar.

Por trás da expansão do jiu-jítsu nos Estados Unidos da América promovida, sobretudo, por Rórion, houve uma tentativa de minimizar, e em alguns momentos de omitir, o papel preponderante de Carlos Gracie na história do jiu-jítsu no Brasil e também da dinastia familiar (GRACIE, 2008, p. 547).

Esse pequeno excerto propicia uma breve reflexão acerca dos tensionamentos existentes no seio da família, e que no decorrer do livro são expostos a partir de diversos depoimentos dos agentes envolvidos. Nos anos iniciais da década de 1990, nos Estados Unidos, Rórion Gracie concebeu um evento (Ultimate Figthing Championship) no qual lutadores de distintas modalidades ou artes marciais se enfrentariam em combates reais, com sentido de provar a eficiência do jiu-jítsu. Os sucessivos êxitos dos lutadores de jiu-jítsu nesses torneios chamaram a atenção das mídias e da comunidade das lutas. No entanto, segundo Reila, a história do desenvolvimento dessa modalidade foi reelaborada por Rórion a partir de interesses próprios. Rórion atribui ao próprio pai, Hélio Gracie, irmão mais novo de Carlos, o aperfeiçoamento das técnicas do jiu-jítsu japonês, negligenciando a participação de Carlos Gracie, o precursor da modalidade na família. A partir desses conflitos de interesse Reila se propõe a recontar a história da modalidade, tendo como figura principal seu pai, Carlos Gracie, evidenciando dessa forma que a produção da obra está eivada por interesses familiares.

A autora destaca em sua obra que a disseminação do jiu-jítsu no Brasil, nos anos de 1920, esteve pautada na estratégia dos desafios. Os Gracie, convencidos de que as técnicas do jiu-jítsu eram mais eficientes do que as de outras modalidades de combate e artes marciais, desafiavam sistematicamente outros lutadores com o intuito de provar a supremacia do jiu-jítsu. No entanto, as dificuldades em estabelecer uma regulamentação que agradasse lutadores de modalidades tão distintas como a capoeira, a luta romana, o boxe e o jiu-jítsu apresentavam-se como um dos principais entraves para a organização dos confrontos intermodalidades. Não 
raro, algumas dessas lutas eram realizadas sem um acordo prévio acerca da regulamentação, tais embates ficaram conhecidos como "vale-tudo", ou seja, tratava-se de combates intermodalidades que ocorriam mesmo sem o preestabelecimento de um conjunto de regras. Dessa maneira, é possível pensar que a popularização e a disseminação do jiu-jítsu dependiam, de certa maneira, do sucesso dos lutadores dessa arte marcial em tais confrontos.

\section{A BIOGRAFIA E AS NOTÍCIAS JORNALÍSTICAS: TENSIONAMENTOS}

No que se refere aos tensionamentos entre a biografia em questão e as fontes jornalísticas selecionadas, o primeiro ponto a ser destacado consta no fato de que Mitsuyo Maeda teria sido o precursor do jiu-jítsu no Brasil. Lembrando que Maeda, ou Conde Koma, como também era conhecido, chegou ao país somente no ano de 1914, fazendo apresentações de jiu-jítsu e participando de confrontos intermodalidades em alguns teatros da então capital federal, Rio de Janeiro. Mais tarde, em 1915, Maeda fixou residência na cidade de Belém/ PA, onde começou a ensinar as técnicas do jiu-jítsu e entre seus alunos estava Carlos Gracie (GRACIE, 2008).

No entanto, já no ano de 1908, o periódico Gazeta de Noticias publicava extensa reportagem acerca do retorno do navio-escola da Marinha brasileira de uma viagem de circumnavegação. Tal matéria apresentava dois japoneses cuja função era a de instruir os marinheiros brasileiros: "Como já referimos vieram a bordo do 'Benjamin' os professores japonezes do 'JiuJitsu', Sada Miyako e M. Kakihara, especialmente contractados para instructores dos nossos marinheiros" (GAZETA DE NOTICIAS, 17 dez. 1908, p.4).

Tratando agora da estada dos dois japoneses no Brasil o jornal Gazeta de Notícias publicava: "Dos nossos marinheiros que já se acham preparados no jogo do Jiu-Jitsu, alguns seguirão para instruírem os aprendizes da escola do estado da Bahia e outros ficarão aqui como instructores da escola desta capital" (GAZETA DE NOTICIAS, 27 jun. 1909, p.8). Não foi possível, por meio das fontes elencadas para este estudo, precisar por quanto tempo os dois estrangeiros ministraram instrução aos marinheiros brasileiros, porém esses breves excertos apontam para uma continuidade dos treinamentos.

Todavia, a maioria das publicações que tratam da história do jiu-jítsu no Brasil referese à chegada dessa modalidade no ano de 1914, tendo como seu precursor Mitsuyo Maeda. A presença de Sada Miyako nesse processo é praticamente inexistente. Em sua obra, Reila Gracie (2008) faz apenas duas menções a Sada Miyako. Na primeira delas afirma que "Sada Miyako, que se dizia lutador de jiu-jítsu, e que fora vítima de uma farsa" (GRACIE, 2012, p. 70). A autora evidencia, assim, certa desconfiança quanto ao fato de Miyako ser efetivamente um lutador de jiu-jítsu. Esta dúvida com relação a Miyako acaba por legitimar a versão de que Maeda foi o pioneiro do jiu-jítsu no Brasil.

Na segunda menção a Sada Miyako, a autora discorre sobre a suposta farsa da qual o lutador japonês foi vítima, em um confronto contra um capoeirista brasileiro.

Antes de iniciar a luta com Cyríaco, famoso capoeira carioca, Miyako estendera-the a mão e, em troca recebera um violento pontapé no rosto. Este confronto aconteceu em 1909, no Pavilhão Internacional. Ao tomar conhecimento do acontecido, Carlos ficou furioso com o que considerou uma deslealdade (GRACIE, 2008, p.70).

90 navio-escola Benjamin Constant foi construído na França, em 1892, e foi o terceiro navio de guerra da frota da Marinha brasileira a realizar a viagem de circum-navegação (GIRAUD, 9 set. 2013). 
Porém os jornais daquele período noticiaram tal disputa de maneira um tanto distinta, como é possível observar no exemplo abaixo:

\begin{abstract}
À hora determinada, apresentou-se o mestre japonez Sada Miako, que, como se sabe, desafiava a qualquer pessoa para luctar, prometendo prêmios àquelle que o conseguisse subjugar. Por várias vezes alguns campeões se apresentaram no tablado, e, entretanto, o terrível japonez facilmente os matava. Hontem coube a vez de Cyriaco Francisco da Silva luctar com o valente Miako. Não quiz, a principio, o japonez aquiescer ao desafio; mas, a protestos energicos do publico, aceitou-0. Uma vez no tablado, Cyriaco, crioulo ligeiro, de 38 annos de idade, campista, desenvolveu o seu ataque: ora pulava como um gato, ora abaixava-se tanto, que parecia estar sentado. 0 japonez esperava o momento de ataque; porém, Cyriaco, dando rápida baixada, mandou-lhe violento cangapé, - um rabo de arraia, na giria da capoeiragem - de encontro ao parietal direito, que produziu a queda immediata do japonez. Cyriaco estava descalso. Foi um delirio de applausos (O PAIZ, 2 maio 1909, p. 2).
\end{abstract}

A partir deste excerto, é possível notar algumas discrepâncias entre a narrativa do livro de Reila Gracie e a fonte jornalística. Enquanto a autora nega a ocorrência da luta, considerando que antes mesmo de a disputa começar, Cyríaco teria cometido uma deslealdade, o jornal Gazeta de Noticias descreve o combate de maneira muito distinta. Além disso, este trecho coloca em suspeição outra passagem do livro, no qual Reila afirma que a luta entre Carlos Gracie e o capoeirista Samuel teria sido a primeira luta pública de vale-tudo no Brasil.

A luta entre Carlos Gracie e o capoeira Samuel foi realizada na Associação Cristã de Moços, e o juiz foi um professor de educação física e praticante de luta grecoromana chamado Manoel Rufino dos Santos. Sem conseguir definir as regras que iriam nortear a luta, Carlos preferiu lutar sem regras e protagonizou com Samuel a primeira luta de vale-tudo, inaugurando essa modalidade de combate nos ringues brasileiros (GRACIE, 2008, p. 71).

Dessa maneira, torna-se possível perceber que as memórias narradas por Reila Gracie apontam para um pioneirismo de seu pai nos confrontos intermodalidades. A desqualificação de Miyako como lutador de jiu-jítsu, a reformulação do discurso acerca da luta contra Cyríaco e, por fim, o estabelecimento do pioneirismo de Carlos Gracie como o precursor deste tipo de confronto.

Vale aqui destacar que diversos jornais da cidade do Rio de Janeiro ${ }^{10}$, já nas duas primeiras décadas do século XX, estampavam em suas páginas várias notícias acerca de lutas intermodalidades que envolviam lutadores de boxe, de luta romana, de jiu-jítsu e do jogo da capoeira. No entanto, a biografia de Carlos Gracie aponta para uma primazia do jiu-jítsu em relação às outras modalidades.

Outro ponto discrepante entre a biografia de Carlos Gracie e fontes jornalísticas referese à inauguração da primeira academia de jiu-jítsu da cidade do Rio de Janeiro e a relação com Donato Pires dos Reis.

No capítulo 7 da obra, intitulado "1925 - Academia Gracie, o sonho vira realidade", Reila escreve que, ao retornar ao Rio de Janeiro, Carlos Gracie alugou uma casa na rua Marquês de Abrantes, 106, imóvel este que serviu ao mesmo tempo como residência para parte da família e também como a primeira sede da "Academia Gracie de Jiu-Jitsu". No entanto as fontes jornalísticas apontam para uma versão distinta. Vários jornais da cidade do Rio de Janeiro, entre eles o Correio da Manhã, o Diário de Notícias e A Noite, noticiaram que a inauguração da

10 A Epoca, A Noite, Correio da Manhã, Diário de Noticias, Jornal do Brasil, O Paiz, A Manhã, Revista da Semana, Gazeta de Noticias, O Imparcial, O Seculo, O Tempo, Diario Carioca, entre outros. 
academia de jiu-jítsu se deu no dia 6 de setembro de 1930, ou seja, cinco anos depois da data mencionada por Reila. "Realisou-se, sabbado, a inauguração da Academia de Jiu-Jitsu, á rua Marquez de Abrantes n.106, com a presença dos representantes da imprensa desta capital á qual foi dedicada a funcção de provas preliminares" (A NOITE, 8 set. 1930, p. 7). Possivelmente com o objetivo de dar publicidade ao evento, os envolvidos com a academia convidaram parte da imprensa escrita da cidade do Rio de Janeiro. Atendendo ao convite, vários jornalistas estiveram presentes à referida inauguração, por tal motivo este acontecimento foi amplamente noticiado por periódicos da então capital federal, possibilitando uma análise detalhada acerca deste acontecido.

Além disso, outro fato relacionado à academia de jiu-jítsu merece destaque. Donato Pires dos Reis foi citado quatro vezes no livro de Reila. Na primeira delas, no início da década de 1920, Donato, que também havia aprendido jiu-jítsu com Conde Koma, convidou Carlos Gracie para auxiliá-lo nas aulas de jiu-jítsu que ministrava para a Polícia Especial de Belo Horizonte, convite prontamente aceito por Carlos. Na segunda menção, datada de 1931, Donato já era considerado um desafeto dos Gracie por ter ministrado aulas de jiu-jítsu a Manoel Rufino dos Santos, renomado atleta de luta romana e adversário de Carlos Gracie em um confronto intermodalidade. Na terceira alusão, também referente ao ano de 1931, Donato era ameaçado e também desafiado por integrantes da família Gracie. Por fim, Reila afirma que, naquele mesmo ano, Donato Pires dos Reis desapareceu da cidade do Rio de Janeiro sem mais dar notícias.

Portanto, segundo a obra de Reila Gracie, não existe qualquer relação entre Donato Pires dos Reis e a academia de jiu-jítsu localizada na rua Marquês de Abrantes. Entretanto os periódicos da cidade do Rio de Janeiro apresentam outra versão acerca de tais fatos. 0 jornal Diario de Noticias, em longa matéria, aqui sintetizada, publicou:

\begin{abstract}
A 'Academia de Jiu-Jitsu' do Rio de Janeiro, tem sua sede á rua Marquez de Abrantes n. 106. Foi fundada por um desses brasileiros de energia e acção, um paraense, o Sr. Donato Pires dos Reis. Moço embora, de estatura meã, ágil e lépido, o Sr. Donato Pires dos Reis é um perfeito especialista de jiu-jitsu. Aprendeu este esporte com os mestres japoneses. A 'Academia de Jiu-Jitsu' conta com três professores: o próprio Sr. Pires dos Reis, o Sr. Carlos Gracie e o Sr. Jorge Gracie, este último monitor. A Academia, apesar de fundada há poucos dias, conta actualmente com 12 a 15 alumnos, perfeitamente seleccionados (DIARIO DE NOTICIAS, 7 set. 1930, p. 23).
\end{abstract}

O jornal Correio da Manhã, também em longa reportagem, aqui editada, discorre sobre a inauguração da referida academia.

Com a presença dos representantes da imprensa inaugurou-se Sabbado a Academia de Jiu-Jitsu á rua Marquez de Abrantes numero 106, sob a direção do professor Sr. Donato Pires dos Reis, a qual conta com optimos professores, como o Sr. Carlos Gracie, campeão do Brasil e o Sr. Jorge Gracie, jovem de 18 annos, que também pertence ao corpo docente e é um ágil lutador (CORREIO DA MANHÃ, 9 set. 1930).

De maneira semelhante, o periódico $A$ Noite também publicou nota acerca da inauguração da academia de jiu-jítsu: "[...] É diretor da escola o professor Sr. Donato Pires dos Reis, o qual, juntamente com os professores Carlos Gracie e Jorge Gracie, ministrarão [sic] 0 ensino a nossa mocidade" (A NOITE, 8 set. 1930, p. 7). 
As três fontes jornalísticas acima elencadas apresentam outra versão acerca da fundação da academia de jiu-jítsu, a começar pelo seu nome, que segundo Reila seria "Academia Gracie de Jiu-Jitsu" (REILA, 2012, p.63), porém os periódicos a apresentavam como "Academia de Jiu-Jitsu do Rio de Janeiro".

Outro ponto problemático consiste no "apagamento" da figura de Donato Pires dos Reis na biografia de Carlos Gracie. Donato é majoritariamente apresentado na obra de Reila como um desafeto da família e sua participação como fundador, diretor e professor da academia de jiu-jítsu foi "esquecida", condição necessária para que a tentativa de "enquadramento de memória" (POLLAK, 1992) por parte de Reila Gracie prosseguisse de modo homogêneo. Vale aqui ressaltar que os jornalistas que realizaram a cobertura da inauguração da academia atribuíam certo protagonismo a Donato, tendo este cedido longa entrevista ao jornal Diário de Notícias (1930), na qual discorria sobre as características do jiu-jítsu e os métodos de ensino utilizado na academia. Tal entrevista é ilustrada com duas fotos, sendo que uma delas (Figura 1) apresenta Donato Pires dos Reis ao centro, à sua direita Carlos Gracie (ambos de terno) e de roupão, à esquerda, George Gracie, abaixo da foto a seguinte legenda: "O diretor da Escola com os dois profissionais" (DIARIO DE NOTÍCIAS, 7 set. 1930, p. 23).

Figura 1 - 0 diretor da Escola com os dois profissionais.

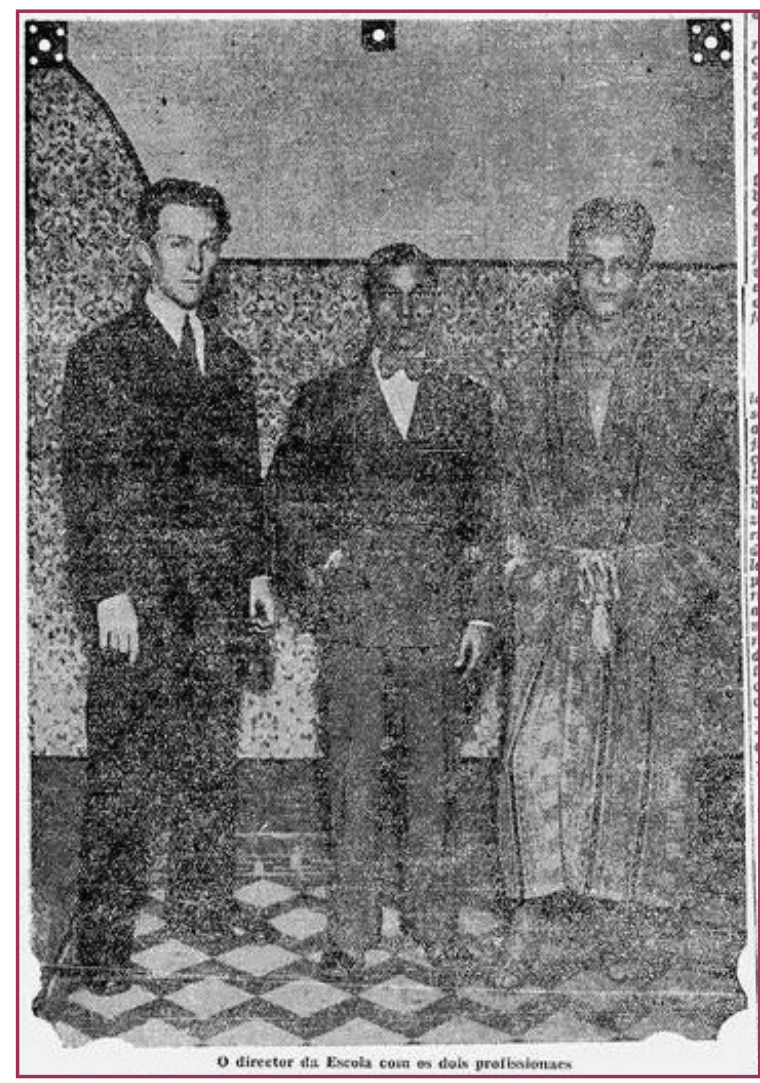

Fonte: DIARIO DE NOTÍCIAS, 7 set. 1930, p. 23. Disponível em: <http://bndigital.bn.br/hemeroteca-digital/> Acesso em: 24 maio 2016

\section{CONSIDERAÇÕES FINAIS}

Sem entrar na discussão acerca da validade do uso da biografia enquanto fonte, mas no sentido de pensar o seu mau uso - sobretudo por parte de pesquisas científicas -, verificou-se a existência de discursos dissonantes entre a biografia e as fontes jornalísticas. 
Sabendo que mesmo o jornal enquanto uma fonte relativamente objetiva traz subjetividades, não cabe apontar que tais matérias representem uma totalidade a respeito dos combates intermodalidades. Todavia, a identificação dessas dissonâncias permite questionar o uso sem tensionamento da referida fonte biográfica.

Nesse sentido, pode-se pensar a hipótese de que Reila Gracie tenha lançado mão de uma tradição inventada, por meio da biografia e aproveitando-se da dimensão fictícia peculiar a tal gênero. Isto é, ao mencionar as querelas intrafamiliares, Reila deixa claro que o seu objetivo é reinserir seu pai, Carlos Gracie, no lugar que lhe é supostamente de direito - 0 de criador de uma dinastia - não apenas do jiu-jítsu mas também do que a autora categoriza como "vale-tudo". Essa hipótese da criação de uma tradição com uma intencionalidade particular é respaldada, também, pela ausência nos jornais de fontes que deem conta de alguns relatos de Reila Gracie.

Dessa forma, é provável que toda reverberação do discurso que institui os Gracie como genitores absolutos dessas modalidades de combate, presente em uma série de textos especializados, tenha tido maior embasamento a partir tradição que seria inventada. Cabendo destacar, ainda, que Reila Gracie escreve apenas como filha de Carlos Gracie, tendo em vista o fato de a autora não ser biógrafa nem atuar em qualquer área relacionada a tal tipo de produção.

\section{REFERÊNCIAS}

AVELAR, Alexandre de Sá. A biografia como escrita da História: das possibilidades de sentido. In: AVELAR, Alexandre de Sá; SCHMIDT, Benito Bisso. Grafia da vida: reflexões e experiências com a escrita biográfica. São Paulo: Letra e Voz, 2012. p. 63 - 80.

BIBLIOTECA NACIONAL DIGITAL. Hemeroteca Digital. Disponível em: < $\underline{\text { http://bndigital.bn.br/ }}$ hemeroteca-digital/>. Acesso em: 24 maio 2016.

BORGES, Vavy Pacheco. Nas pegadas de um leão: notas de pesquisa sobre a vida de Ruy Guerra. In: AVELAR, Alexandre de Sá; SCHMIDT, Benito Bisso. Grafia da vida: reflexões e experiências com a escrita biográfica. São Paulo: Letra e Voz, 2012. p. 83 - 104.

BOURDIEU, Pierre. O poder simbólico. Rio de Janeiro: Bertrand Brasil, 2003.

CANDIDO, Antonio. Literatura e Sociedade. São Paulo: Queiroz, 2000.

CORREIO DA MANHÃ. A inauguração da Academia de Jiu-Jitsu. Rio de Janeiro, 9 set. 1930, p. 8.

DIÁRIO DE NOTÍCIAS. 0 mais admirável meio de defesa pessoal: o Jiu-Jitsu. Rio de Janeiro, 7 set. 1930, p. 23.

GINZBURG, Carlo. Nenhuma ilha é uma ilha: quatro visões da literatura inglesa. São Paulo: Companhia das Letras, 2004.

GIRAUD, Laire. A História dos Navios-Escola no Brasil. Brasília: Defesanet, 9 set. 2013.

Disponível em: <http://www.defesanet.com.br/ecos/noticia/12159/A-historia-dos-navios-escola-noBrasil/>. Acesso em: 5 dez. 2013. 
GRACIE, Reila. Carlos Gracie: o criador de uma dinastia. 4. ed. Rio de Janeiro: Record, 2008.

HOBSBAWN, Eric; RANGER, Terence. A invenção das tradições. Rio de Janeiro: Nova Fronteira, 2012.

LISE, Riqueldi Straub. Entre diretos, ceintures avant, chaves de braço e rabos de arraia: os primórdios dos combates intermodalidades na cidade do Rio de Janeiro (1909-1929). 2014. 149f. Dissertação (mestrado) - Programa de Pós-Graduação em Educação Física, UFPR, Curitiba, 2014.

LUCA, Tania Regina de. História dos, nos e por meio dos periódicos. In: PINSKY, C. B. (Org.). Fontes Históricas. São Paulo: Contexto, 2008. p. 111-153.

MARQUES, Franciele; GONÇALVES, Luana lensen; KROTH, Maicon Elias. Os critérios de noticiabilidade do jornalismo especializado: a revista Tatame e a tematização do MMA feminino. In: CONGRESSO DE CIÊNCIAS DA COMUNICAÇÃO NA REGIÃO SUL, 14. Santa Cruz do Sul, 2013. Disponível em: < http://portalintercom.org.br/anais/sul2013/resumos/R35-0162-1. pdf>. Acesso em: 21 abr. 2017.

NEWS MMA. Como tudo começou, uma histórica rica do MMA desde o seu berço, o Brasil. 2012. Disponível em: <https://newsmma.wordpress.com/2012/01/04/como-tudo-comecou-umahistorica-rica-do-mma-desde-o-seu-berco-o-brasil/>. Acesso em: 13 maio 2016.

A NOITE. A inauguração da Academia de Jiu-Jitsu, Rio de Janeiro, 8 set. 1930, p. 7.

NUNES, Alexandre Velly; RUBIO, Katia. As origens do judô brasileiro: a árvore genealógica dos medalhistas olímpicos. Revista Brasileira de Educação Física e Esporte, v.26, n.4, p.667-678, out./dez. 2012.

OLIVEIRA, Eduardo. A história dos Gracie: o surgimento do vale-tudo. 15 abr. 2011.

Disponível em: <http://esporte.ig.com.br/lutas/a+historia+dos+gracie+o+surgimento+do+valetudo/ n1300076934073.html>. Acesso em: 12 maio 2016.

O PAIZ. Os matchs do internacional. Rio de Janeiro, 2 maio 1909, p. 2.

POLLAK, Michael. Memória e Identidade Social. Estudos Históricos, v. 5, n. 10, p. 200-212, 1992.

RUDNICK, Fernando. Berço do vale-tudo, Brasil vira o mercado mais cobiçado do UFC. 12 jan. 2012. Disponível em: <http://www.gazetadopovo.com.br/esportes/berco-do-vale-tudo-brasil-virao-mercado-mais-cobicado-do-ufc-7rmjwi7wir9j9h5h3x3gyi3bi>. Acesso em: 18 maio 2016.

O SÉCULO. Exposição Nacional. Rio de Janeiro, 25 dez. 1908, p. 2.

SILVA, Kalina Vanderlei; SILVA, Maciel Henrique (Org.). Dicionários de Conceitos Históricos. São Paulo: Contexto, 2005. p. 189-191.

TATAME ON LINE. A história do MMA (Vale Tudo): Saiba tudo sobre o UFC e o Pride. 2 jun. 2014. Disponível em: <http://tatameonline.com/a-historia-do-mma-vale-tudo-saiba-tudo-sobre-o-ufce-o-pride/>. Acesso em: 12 maio 2016.

VIEIRA, Maria do Pilar de Araújo et al. Imprensa como fonte para pesquisa histórica. Revista do Programa de Estudos Pós-Graduados de História, v.3, n.3, p. 47-54, 1984. 
Apoio:

Capes 